\title{
Exploring the Concept of the (Future) Mobile Office
}

Christian P. Janssen

Utrecht University

Heidelberglaan 1, 3584 CS

Utrecht, The Netherlands

c.p.janssen@uu.nl

Andrew L. Kun

University of New Hampshire

Electrical and Computer Eng.

Durham, NH 03824, USA

andrew.kun@unh.edu

Stephen Brewster

University of Glasgow

Glasgow, G12 8RZ, UK

Stephen.Brewster

@glasgow.ac.uk
Linda Ng Boyle

University of Washington

Seattle, WA 98195-2650, USA

linda@u.washington.edu

Duncan P. Brumby

UCL Interaction Centre

University College London

London, United Kingdom

d.brumby@ucl.ac.uk

Lewis L. Chuang

Ludwig-Maximilians-Universität

München

Frauenlobstr. 7a, 80337

München, Germany

lewis.chuang@um.ifi.Imu.de

Permission to make digital or hard copies of part or all of this work for personal or Permission to make digital or hard copies of part or all of this work for personal or
classroom use is granted without fee provided that copies are not made or distribute classroom use is granted without fee provided that copies are not made or distributed for profit or commercial advantage and that copies bear this notice and the full citation on the first page. Copyrights for hird-party compone

Copyright held by the owner/author(s).

AutomotiveUI '19 Adjunct, 11th Intl Conference on Automotive User Interfaces and Interactive Vehicular Applications, September 21-25, 2019, Utrecht, Netherlands ACM 978-1-4503-6920-6/19/0920.

$10.1145 / 3349263.3349600$ 


\section{Introduction}

Drivers occasionally perform non-driving related activities in the car [2], requiring them to interleave attention [4]. In nonautomated vehicles, such activities are unsafe. Moreover, even for passengers that perform non-driving tasks, such activities might be limited by the amount of space you have to work, or by creating nausea and motion sickness.

In this video (available online here: [5]) we present a concept of how a combination of a SAE Level 3 automated vehicle [3] with augmented reality might offer a solution to some of these issues. Research suggests that if automated vehicles become more reliable, and if full attention of the human driver to the road is not needed and required for safe driving, then drivers would like to dedicate more time to work and play [7], including activities that are being done in other transportation modes such as trains [10]. In other words, our cars might turn into mobile offices [1].

Concepts of interaction with augmented reality have been tested before in driving scenarios (e.g., [9, 8]). Although in that earlier work the scope of the augmented reality technology is limited, in our video we assume that this technology involves and will create new possibilities for interaction with virtual avatars of other remote callers.

Talking through a virtual avatar, that is projected onto the dashboard will allow drivers the ability to occasionally look at the road and the car, while also having a virtual meeting. As the eyes can stay on the road, this might also minimize motion sickness, which is a critical issue for automated vehicles [6].

Taking it even further, there might even be potential for group calls, with multiple avatars being present. Such setups might be used for both work (e.g., group office meetings) and play (e.g., remote karaoke).
In the video we also demonstrate the concept of a smart assistant. The assistant responds to subtle gestures of the user (in the video: a hand gesture) to process relevant information from the user. The assistant than uses the information to act in a smart way. In this case: to place a meeting in the agenda of the user.

The video is intended as a playful introduction to a potential technology, and not meant to suggest that eyes-of-the-road is possible in current vehicles. Don't forget to look for our bloopers right after the credit roll ;-)

\section{Acknowledgements}

This video idea was generated at the seminar on "Users and automated driving systems: How will we interact with tomorrow's vehicles?" held at Schloss Dagstuhl, Germany (Seminar number 19132). We gratefully acknowledge the organizers of the seminar, Schloss Daghstul, and the other members of the seminar for their contributions. Andrew Kun and Linda Boyle were in part supported by NSF grant CMMI-1840085. The funding organization had no involvement in the nature or design of this research.

\section{REFERENCES}

1. Lewis L. Chuang, Stella F. Donker, Andrew L. Kun, and Christian P. Janssen. 2018. Workshop on The Mobile Office. In Adjunct Proceedings of the 10th International Conference on Automotive User Interfaces and Interactive Vehicular Applications (AutomotiveUl '18). ACM, New York, NY, USA, 10-16. DOI :

http://dx.doi.org/10.1145/3239092.3239094

2. Thomas A Dingus, Feng Guo, Suzie Lee, Jonathan F Antin, Miguel Perez, Mindy Buchanan-King, and Jonathan Hankey. 2016. Driver crash risk factors and prevalence evaluation using naturalistic driving data. Proceedings of the National Academy of Sciences 113, 
10 (2016), 2636-2641.

3. SAE International. 2018. Taxonomy and definitions for terms related to driving automation systems for on-road motor vehicles (Surface Vehicle Recommended Practice: Superseding J3016-2016. (June 2018). https :

//www.sae.org/standards/content/j3016_201806/

4. Christian P. Janssen, Shamsi T. Iqbal, Andrew L. Kun, and Stella F. Donker. 2019a. Interrupted by my car? Implications of interruption and interleaving research for automated vehicles. International Journal of Human-Computer Studies 130 (2019), 221-233. DOI : http://dx.doi.org/10.1016/j.ijhcs.2019.07.004

5. Christian P. Janssen, Andrew L. Kun, Stephen Brewster, Linda Ng Boyle, Duncan P. Brumby, and Lewis L. Chuang. 2019b. [Auto-UI 2019] Exploring the Concept of the (Future) mobile office (video). Video. (12 July 2019). Retrieved July 12, 2019 from https://youtu.be/HrZmSb8NvBg.

6. Andrew L Kun. 2018. Human-Machine Interaction for Vehicles: Review and Outlook. Foundations and
Trends® in Human-Computer Interaction 11, 4 (2018), 201-293.

7. Andrew L Kun, Susanne Boll, and Albrecht Schmidt. 2016. Shifting gears: User interfaces in the age of autonomous driving. IEEE Pervasive Computing 1 (2016), 32-38.

8. Andrew $L$ Kun, Hidde van der Meulen, and Christian $P$ Janssen. 2017. Calling while driving: An initial experiment with HoloLens. In Proceedings of the Ninth International Driving Symposium on Human Factors in Driver Assessment, Training and Vehicle Design. University of lowa, 200-206.

9. Andrew L Kun, Hidde van der Meulen, and Christian P Janssen. 2019. Calling while Driving Using Augmented Reality: Blessing or Curse? PRESENCE: Virtual and Augmented Reality 27, 1 (2019), 1-14.

10. Bastian Pfleging, Maurice Rang, and Nora Broy. 2016. Investigating user needs for non-driving-related activities during automated driving. In Proceedings of the 15th international conference on mobile and ubiquitous multimedia. ACM, 91-99. 